\title{
HÍBRIDOS DE MILHO INOCULADOS COM Azospirillum brasilense SOB DIFERENTES DOSES DE NITROGÊNIO
}

\author{
RAFAEL CADORE ${ }^{1}$, ANTÔNIO PAULINO DA COSTA NETTO ${ }^{1}$, EDÉSIO FIALHO DOS REIS ${ }^{1}$, \\ VILMAR ANTONIO RAGAGNIN ${ }^{1}$, DOUGLAS SIQUEIRA FREITAS ${ }^{1}$, TAYNARA PERES DE LIMA ${ }^{1}$, \\ MARIELI ROSSATO ${ }^{1}$ e ANA CLAUDIA ALVES D'ABADIA ${ }^{1}$
}

\begin{abstract}
${ }^{1}$ Universidade Federal de Goiás - Campus Jatai (UFG-CAJ). Unidade Jatobá - Rodovia BR 364, Km 192, Jataí (GO) CEP: 75801-615.rafael_s_cadore@hotmail.com,apcnetto@gmail.com,edesio7@brturbo.com.br,vilmar.ragagnin@gmail.com, doug20106@gmail.com,taynarapl@hotmail.com,marieli_1701@hotmail.com,anadabadia@yahoo.com.
\end{abstract}

Revista Brasileira de Milho e Sorgo, v.15, n.3, p. 398-409, 2016

\begin{abstract}
RESUMO - Microrganismos do gênero Azospirillum possuem o potencial de melhorar o desenvolvimento e a produção da cultura do milho. Porém as respostas dos híbridos de milho não são iguais frente à inoculação com estes microrganismos, devido a possível especificidade na interação entre genótipo e microrganismo e os diferentes manejos adotados. Desta forma, objetivou-se com este trabalho avaliar o desenvolvimento e a produtividade de dez híbridos a fim de indicar entre esses híbridos os mais responsivos quando submetidos à inoculação de Azospirillum brasilense e a diferentes doses de nitrogênio em cobertura. Vários caracteres agronômicos foram avaliados como: altura de plantas, altura de inserção da espiga, diâmetro de colmo, teor de clorofila total, tamanho de espiga, número de fileiras da espiga, números de grãos por fileira, massa de 100 grãos e produtividade de grãos. Além dos caracteres agronômicos avaliou-se a atividade da enzima redutase do nitrato em duas diferentes épocas (V4 - V6 e VT). Os híbridos mais produtivos foram o Biogene 7046, Dekalb 310 VT PRO ${ }^{\mathrm{TM}}$ e Agroeste 1596 VT PRO $^{\mathrm{TM}}$. O incremento das doses de nitrogênio aumentou o diâmetro do colmo, teor de clorofila total, comprimento da espiga, grãos por fileira e a produção de grãos.
\end{abstract}

Palavras-chave: adubação nitrogenada; bactérias diazotróficas; safrinha.

\section{MAIZE HYBRIDS INOCULATED WITH Azospirillum brasilense UNDER DIFFERENT DOSES OF NITROGEN}

\begin{abstract}
Microorganisms of the genus Azospirillum have the potential to improve the development and production of maize. However, the response of corn hybrids is not equal under inoculation with these microorganisms due to the specificity in the interaction between genotype and microorganism and the use of different managements. Thus, the objective of this work was to evaluate the development and productivity of ten hybrids to indicate the most responsive when subjected to inoculation with Azospirillum brasilense and different doses of nitrogen fertilization. Several agronomic characters were evaluate as plant height, ear insertion height, stem diameter, total chlorophyll content, ear size, number of rows grains per ear, number of grains per row, mass of 100 grains and grain yield. In addition to the agronomic traits the activity of the enzyme nitrate reductase was evaluated in two different seasons (V4 - V6 and VT). The most productive hybrids were Biogene 7046, Dekalb 310 VT PRO TM and Agroeste 1596 VT PRO TM. The increment of nitrogen increased stem diameter, total chlorophyll content, ear length, grains per row and grain production.
\end{abstract}

Keywords: dizotrofic bacterias; nitrogen fertilization; second harvest. 
O Brasil é pioneiro na inoculação de sementes com organismos envolvidos no processo de fixação biológica de nitrogênio. Prova disto é o uso massivo de inoculantes do gênero Rhizobium na cultura da soja. A partir daí, surge o interesse na obtenção dos benefícios proporcionados pelos diazotróficos do solo para os cultivos de não leguminosas. O país evoluiu bastante neste sentido e hoje é possível encontrar comercialmente inoculantes com bactérias do gênero Azospirillum recomendados para as mais diversas espécies pertencentes à família Poaceae, sendo comumente utilizados no cultivo de milho.

A bactéria Azospirillum brasilense é uma bactéria de vida livre no solo, que apresenta capacidade de fixação biológica de nitrogênio associativa com as plantas, mas sem a complexidade da formação de nódulos.

Devido à alta demanda da cultura do milho em nitrogênio e à importância deste nutriente para se atingir bons níveis de produtividade, torna-se importante a busca de mecanismos que possam maximizar o uso e a assimilação de $\mathrm{N}$ pelas plantas. Neste sentido, a inoculação com microrganismos capazes de fixar nitrogênio atmosférico em gramíneas pode ser uma boa alternativa, apesar de não substituir por completo a aplicação de $\mathrm{N}$ via fertilizantes. Há trabalhos que demonstram a redução significativa das doses de $\mathrm{N}$ via fertilizantes com o uso da inoculação sem comprometer a produtividade (Hungria et al., 2010).

Visando às viabilidades técnica e econômica da segunda safra, o uso de inoculantes pode ser vantajoso não apenas pela fixação de $\mathrm{N}$, mas também pela produção de fitormônios que estimulam o crescimento das raízes, implicando assim em vários outros efeitos que podem incrementar a absorção de água e sais minerais e maior tolerância a estresses como salinidade e seca (Bashan et al., 2004). Desta forma, a avaliação e identificação de genótipos de milho com maior capacidade de aquisição e assimilação de N, juntamente com maior eficiência na associação com bactérias diazotróficas promotoras de crescimento vegetal, podem maximizar a produção em condições adversas que podem implicar em redução na aplicação de fertilizantes nitrogenados. Acredita-se que a população de Azospirillum brasilense pode variar de híbrido para híbrido, em função das diferentes características qualitativas e quantitativas dos exudatos radiculares. Os produtos depositados pelas plantas na rizosfera não constituem apenas fonte de carbono para o crescimento bacteriano, mas também servem para promover a quimiotaxia, que melhora a interação microrganismo/rizosfera, como é o caso dos flavonoides (Rengel, 2002).

Com o avanço e a evolução do nível tecnológico da segunda safra, o número de híbridos disponíveis no mercado para o produtor é cada vez maior e, portanto, torna-se necessário o conhecimento do comportamento destes híbridos frente à inoculação visando a maiores resposta e capacidade de assimilação e utilização de N. Assim, objetivou-se com este trabalho avaliar o desenvolvimento e a produtividade de dez híbridos de milho a fim de indicar os mais responsivos quando submetidos a inoculação de Azospirillum brasilense e a diferentes doses de nitrogênio em cobertura.

\section{Material e Métodos}

O experimento foi conduzido no ano agrícola de 2013 em segunda safra, no campo experimental da Universidade Federal de Goiás, em Jataí, GO, localizado a $17^{\circ} 66^{\prime} \mathrm{S}$ e $51^{\circ} 33^{\prime} \mathrm{O}$ com altitude média de 700 m. O município de Jataí está situado no Sudoeste goiano, com temperatura e precipitação média anual 
de $22{ }^{\circ} \mathrm{C}$ e $1.800 \mathrm{~mm}$, respectivamente. Os dados de precipitação pluviométrica e as temperaturas mínima e máxima registradas durante a realização do experimento são apresentados na Figura 1. Durante a condução do experimento, a precipitação total foi de $627,40 \mathrm{~mm}$ e a temperatura variou de 6 a $34,9^{\circ} \mathrm{C}$.

O solo foi classificado como Latossolo vermelho distroférrico com textura argilosa, cujas características químicas na camada de $0-20 \mathrm{~cm}$ foram: $\mathrm{pH}$ $\left(\mathrm{CaCl}_{2}\right), 5,1 ; \mathrm{P}, 5,3 \mathrm{mg} \mathrm{dm}^{-3} ; \mathrm{K}, 0,10 \mathrm{cmol}_{\mathrm{c}} \mathrm{dm}^{-3} ; \mathrm{Ca}$, $1,55 \mathrm{cmol}_{\mathrm{c}} \mathrm{dm}^{-3} ; \mathrm{Mg}, 0,6 \mathrm{cmol}_{\mathrm{c}} \mathrm{dm}^{-3} ; \mathrm{Al}, 0,13 \mathrm{cmol}_{\mathrm{c}}$ $\mathrm{dm}^{-3}$; CTC 8,7, $\mathrm{cmol}_{\mathrm{c}} \mathrm{dm}^{-3}$ e H+Al, 6,5 $\mathrm{cmol}_{\mathrm{c}} \mathrm{dm}^{-3}$. $\mathrm{A}$ área onde foi conduzido o experimento estava em pousio (safra 2012/2013) sob vegetação espontânea, sendo que nos últimos quatro anos o local foi ocupado por sucessão soja/milho no sistema de plantio direto.
$\mathrm{O}$ experimento foi instalado em delineamento em blocos casualizados, com quatro repetições, no esquema fatorial $10 \mathrm{x} 4$, sendo o primeiro fator referente a híbridos comerciais, recomendados para segunda safra na região do Sudoeste goiano, totalizando dez híbridos (Dekalb 390 VT PROTM, Dekalb 310 VT PROTM, Biogene 7046, Biogene $7049 \mathrm{H}^{\circledR}$, Biogene $7061 \mathrm{H}^{\circledR}$, Biogene $7037 \mathrm{H}^{\circledR}$, Agroeste $1581 \mathrm{VT}$ PRO $^{\text {TM }}$, Agroeste 1596 VT PRO ${ }^{\text {TM }}$, Riber 9005 VT PROTM $^{\mathrm{TM}}$, Riber 9006 VT PROTM); no segundo fator, os tratamentos correspondem a T1: sem cobertura e sem inoculação; T2: sem cobertura e com inoculação de $A$. brasilense; T3: aplicação de $35 \mathrm{~kg} \mathrm{ha}^{-1}$ de N em cobertura 15 dias após a emergência (V4) com inoculação de $A$. brasilense; T4: aplicação de $70 \mathrm{~kg} \mathrm{ha}^{-1}$ de $\mathrm{N}$ em cobertura 15 dias após a emergência (V4) com inoculação de $A$. brasilense.

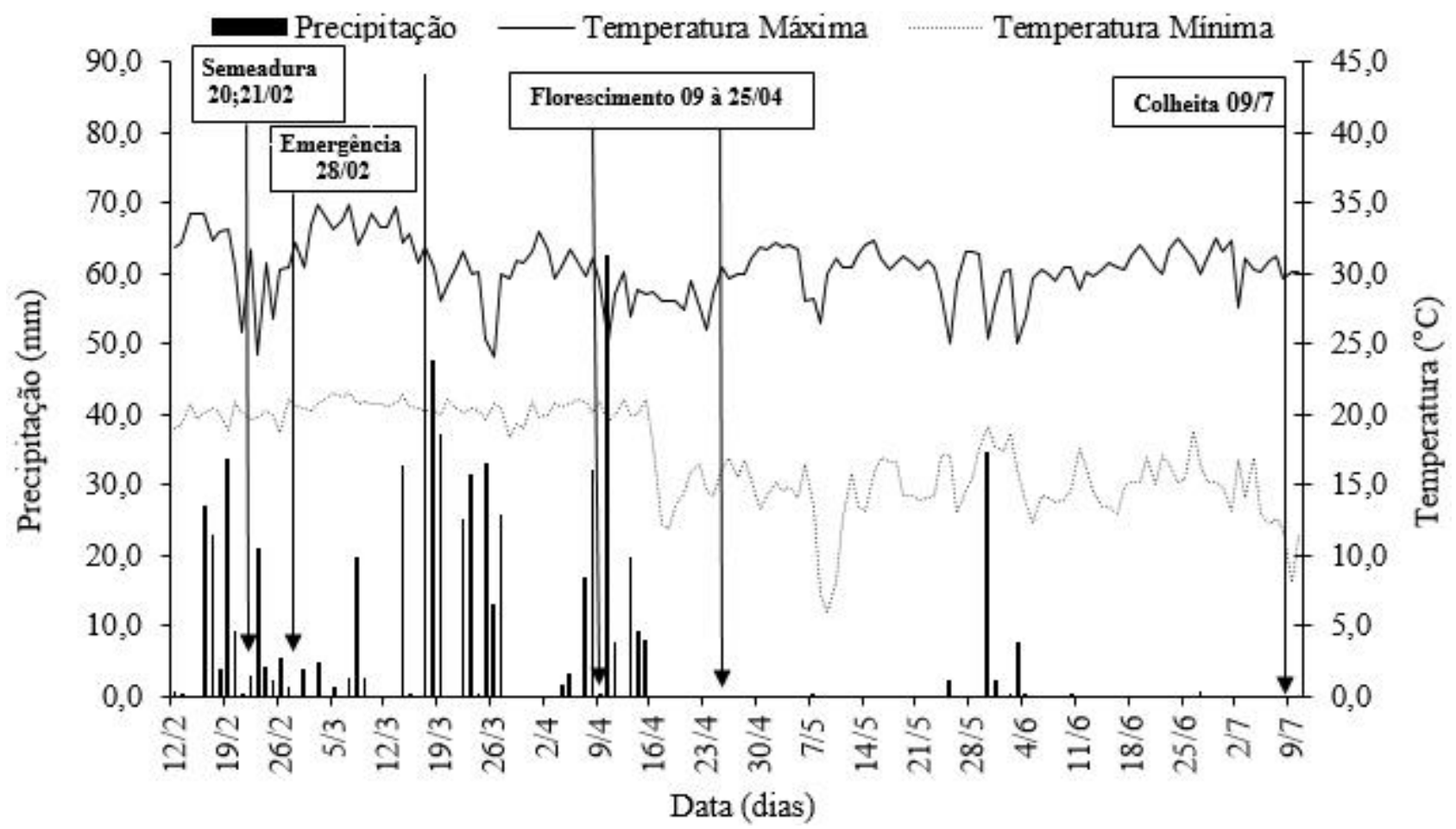

Figura 1. Precipitação pluviométrica $(\mathrm{mm})$ e temperaturas máxima e mínima $\left({ }^{\circ} \mathrm{C}\right)$ registradas no período de fevereiro a julho de 2013. 
Em todos os tratamentos, foram aplicados 30 $\mathrm{kg} \mathrm{ha}^{-1}$ de $\mathrm{N}$ na semeadura e o inoculante utilizado foi com a espécie Azospirillum brasilense estirpes AbV5 + AbV6, com concentração bacteriana de 2,0×10 ${ }^{8}$ UFC por $\mathrm{mL}$, inoculado nas sementes minutos antes da semeadura na dose de $100 \mathrm{~mL}$ para cada $25 \mathrm{~kg}$ de sementes.

A aplicação de nitrogênio em cobertura foi feita a lanço manualmente e a fonte utilizada foi o sulfato de amônio $(20 \% \mathrm{~N})$, quando cada parcela recebeu a quantidade de acordo com o seu tratamento. Também foi realizada juntamente com a adubação de cobertura nitrogenada a adubação com cloreto de potássio ( $60 \%$ $\mathrm{K}_{2} \mathrm{O}$ ) na dose de $80 \mathrm{~kg} \mathrm{ha}^{-1}$ de $\mathrm{K}_{2} \mathrm{O}$ em área total.

Utilizou-se o sistema de plantio direto via dessecação com o herbicida glyphosate $\left(360 \mathrm{~g} \mathrm{~L}^{-1}\right)$ na dose de $4 \mathrm{~L} \mathrm{ha}^{-1}$ para controle da vegetação espontânea, antes da semeadura, que foi realizada nos dias 20 e 21 de fevereiro de 2013. Não houve adição de nenhum ingrediente ativo às sementes, que continham o tratamento de sementes padrão disponibilizado pelas empresas, que consiste no tratamento industrial com fungicida a base de Fludioxonil $25 \mathrm{~g} \mathrm{~L}^{-1}+$ Metalaxil -M $100 \mathrm{~g} \mathrm{~L}^{-1}$ e inseticidas a base de Deltametrina $25 \mathrm{~g}$ $\mathrm{L}^{-1}+$ Pirimifos Metilico $500 \mathrm{~g} \mathrm{~L}^{-1}+$ Tiametoxan 35\% $0,12 \mathrm{~L}^{2} 60.000$ sementes $^{-1}$. A semeadura foi realizada manualmente utilizando marcações nas linhas de semeadura para que todos os híbridos tivessem uma população final de plantas de $57.777,8$ plantas ha ${ }^{-1}$. Na adubação de semeadura, utilizou-se a dose de $30 \mathrm{~kg}$ $\mathrm{ha}^{-1}$ de N, 98,4 kg ha-1 de $\mathrm{P}_{2} \mathrm{O}_{5}$ e 52,5 $\mathrm{kg} \mathrm{ha}^{-1}$ de $\mathrm{K}_{2} \mathrm{O}$, de acordo com os resultados da análise de solo e a expectativa de rendimento da cultura do milho conforme Souza e Lobato (2004). Para o controle de pragas, foram realizadas aplicações com pulverizador costal, dotado de cilindro de $\mathrm{CO}_{2}$ e barra de quatro bicos espaçados em $50 \mathrm{~cm}$, utilizando-se volume de calda de $200 \mathrm{~L} \mathrm{ha}^{-1}$. O controle de plantas daninhas foi realiza- do no estádio V3 da cultura utilizando-se mistura de herbicidas Atrazine (1,5 $\left.\mathrm{L} \mathrm{ha}^{-1}\right)+$ Tembotriona $(0,24$ $\mathrm{L} \mathrm{ha}^{-1}$ ). No estádio V9, procedeu-se à aplicação de fungicida a base de Piraclostrobina + Epoxiconazol $\left(0,75 \mathrm{~L} \mathrm{ha}^{-1}\right)$ e foram realizadas aplicações de inseticidas visando ao controle de Spodoptera frugiperda, Diabrotica speciosa e Rhopalosiphum maidis nos estádios iniciais da cultura e no estádio V12.

As parcelas foram constituídas de cinco linhas espaçadas em $0,45 \mathrm{~m}$ com $5 \mathrm{~m}$ de comprimento (sendo as três linhas centrais consideradas como área útil). A primeira variável dependente analisada foi a quantificação da atividade da enzima redutase do nitrato aos 21 dias após a emergência (DAE) entre os estádios V4-V6, período este posterior à aplicação da adubação de cobertura e aos 44 DAE (superprecoce BG $7061 \mathrm{H}^{\circledR}$ ), 48 DAE (DKB $390 \mathrm{VT}^{\text {PRO }}{ }^{\mathrm{TM}}$, BG 7046, BG $7049 \mathrm{H}^{\circledR}$, BG $7037 \mathrm{H}^{\circledR}$, RB 9006 VT PRO precoce) e 50 DAE (DKB $310 \mathrm{VT}^{\mathrm{PRO}}{ }^{\mathrm{TM}}$, AS1581 VT PRO ${ }^{\mathrm{TM}}$, AS 1596 VT PRO $^{\mathrm{TM}}$, RB 9005 VT PRO $^{\mathrm{TM}}$ precoce a semiprecoce) estádio VT, de acordo com a precocidade de cada híbrido para que as coletas fossem sempre realizadas em pré-pendoamento.

A metodologia de quantificação da atividade da enzima nitrato redutase utilizada foi adaptada de Klepper et al. (1971), em que foi coletada a última folha completamente expandida de três plantas diferentes dentro de cada área útil em apenas três blocos, sendo desconsiderado um bloco devido ao grande número de amostras geradas no laboratório. O horário de coleta foi no intervalo das 10:00 às 12:00 h, garantindo assim o período de luz e temperatura adequado para que a atividade enzimática estivesse em pleno funcionamento. Essas folhas foram levadas para o laboratório, onde foram lavadas com água destilada. As folhas foram cortadas em fragmentos de aproximadamente $0,2 \mathrm{~mm}$ de espessura, sendo utilizado $0,2 \mathrm{mg}$ 
de matéria fresca para análise, posteriormente colocado no meio de incubação com a seguinte composição: $5 \mathrm{~mL}$ de solução tampão fosfato $\left(\mathrm{K}_{2} \mathrm{HPO}_{4}+\mathrm{KH}_{2} \mathrm{PO}_{4}\right.$ $\left.0,1 \mathrm{~mol} \mathrm{~L}^{-1}\right), \mathrm{pH} 7,5$; adicionando-se $1 \mathrm{~mL}$ de nitrato de potássio $\left(\mathrm{KNO}_{3} 0,25 \mathrm{~mol} \mathrm{~L}^{-1}\right)$ e $1 \mathrm{~mL}$ de $\mathrm{N}$-propanol $(1 \% \mathrm{v} / \mathrm{v})$. Em seguida, agitaram-se os frascos de vidro em vortex, sendo os mesmos cobertos com papel alumínio para o isolamento da luz e colocando-se em seguida para incubar em B.O.D por $1 \mathrm{~h} \mathrm{a} 30^{\circ} \mathrm{C}$. Após este período, filtrou-se o meio de incubação e, com uma pipeta, foram retiradas alíquotas de $1 \mathrm{~mL}$ de solução de incubação e transferidas para tubos de ensaio com 1,0 $\mathrm{mL}$ de sulfanilamida $0,1 \%$ em $\mathrm{HCl}\left(3,0 \mathrm{~mol} \mathrm{~L}^{-1}\right)$. Em seguida, agitou-se em vortex e, após $30 \mathrm{~min}$, foi adicionado $1 \mathrm{~mL}$ de $\mathrm{N}$-naftil etileno diamina $0,01 \%$, agitando-se novamente em vortex; após $15 \mathrm{~min}$, realizou-se a leitura em espectrômetro a $540 \mathrm{~nm}$ em absorbância.

As absorbâncias obtidas foram comparadas com uma curva padrão de nitrito gerada a partir de quantidades conhecidas de nitrito, sendo expressa a atividade da enzima redutase do nitrato em micromoles de nitrito por hora por grama de matéria fresca ( $\mu$ moles de $\mathrm{NO}_{2}^{-} \mathrm{H}^{-1} \mathrm{~g}^{-1} \mathrm{MF}$ ).

No período posterior à polinização (76 DAE), foram iniciadas as avaliações a campo das características agronômicas. Foram coletadas cinco plantas ao acaso na área útil de cada parcela e mensurados a altura da planta em metros, da superfície do solo até a folha bandeira, além da altura da inserção da primeira espiga, o diâmetro do colmo, mensurado com um paquímetro digital graduado em milímetros, pegandose o segundo internódio acima do colo da planta, e o teor de clorofila total no terço basal da folha oposta e abaixo da espiga, com o aparelho clorofilog CFL 1030, da Falker.

Ao final do ciclo da cultura, foram colhidas todas as espigas da área útil das três linhas centrais, excluindo-se 0,5 $\mathrm{m}$ em cada extremidade da parcela. Para determinações de comprimento, número de grãos por fileira e número de fileiras da espiga, foram utilizadas dez espigas de plantas presentes na área útil da parcela. O comprimento médio de espiga foi determinado através de medidas da base até o ápice da espiga com auxílio de régua. $\mathrm{O}$ número de grãos por fileira foi obtido contando-se o número de grãos de uma fileira de cada uma das dez espigas amostradas e, para o número de fileiras, foram contadas todas as fileiras do material amostrado. Para a massa de 100 grãos, foram contados os grãos de cada parcela com oito repetições e pesados. A produtividade de grãos foi obtida através da colheita das espigas na parcela útil, quando essas espigas foram debulhadas e os grãos foram pesados e posteriormente foi determinado o teor de umidade nos grãos, sendo os dados de produtividade corrigidos para $13 \%$. Também foi necessário realizar a correção de estande em virtude de ocorrência de diferença significativa para essa característica, por meio da equação de correção pela análise de covariância com estande ideal, objetivando uma população final de $57.777,8$ plantas ha-1 ${ }^{-1}$ Os dados de produção foram extrapolados para área de um hectare e expressos em $\mathrm{Mg} \mathrm{ha}^{-1}$. Os efeitos dos fatores das doses de nitrogênio combinadas com Azospirillum brasilense sobre os dez híbridos foram analisados por meio de análise de variância. As médias das variáveis dependentes estudadas foram comparadas pelo teste de Scott-Knott (5\%). As análises foram realizadas por meio do programa Sisvar (Ferreira, 2011).

\section{Resultados e Discussão}

Não houve interação entre os híbridos de milho e as doses de nitrogênio combinadas com a inoculação de Azospirillum brasilense para as variáveis em 
estudo. Em virtude da ausência de interação, cada fator será considerado isoladamente.

Os quadrados médios obtidos na análise de variância encontram-se na Tabela 1. Percebem-se as diferenças entre os híbridos estudados pela significância de todas as variáveis avaliadas para o fator híbrido (H). Para o fator doses de nitrogênio em cobertura combinados com inoculação de Azospirillum brasilense, houve diferença entre os níveis de $\mathrm{N}$ para altura de planta, diâmetro basal do colmo, teor de clorofila total, comprimento de espiga, grãos por fileira e produtividade de grãos (Tabela 1).

As análises das variáveis significativas pelo teste $\mathrm{F}$ foram efetuadas pelo teste de comparação de médias Scott-Knott, ao nível de 5\% de probabilidade. $\mathrm{O}$ primeiro fator analisado separadamente foi híbridos (Tabela 2).

Nos componentes morfológicos dos híbridos, percebe-se para altura de planta que os híbridos Biogene 7046 e Agroeste 1581 VT PRO ${ }^{\mathrm{TM}}$ prevaleceram sobre os demais (Tabela 2). Para altura de inserção da primeira espiga, os maiores valores foram encontrados nos híbridos Dekalb 390 VT PRO ${ }^{\text {TM }}$, Dekalb 310 VT PRO $^{\text {TM }}$ e Agroeste 1581 VT PRO ${ }^{\text {TM }}$. A análise dessas duas variáveis é considerada importante, pois, segundo Li et al. (2007), plantas mais altas e com maior altura de inserção de espiga são mais suscetíveis ao acamamento. Porém, neste estudo não foi observado acamamento de plantas mesmo nos híbridos de grande porte, sugerindo que outros fatores que contribuem para a predisposição ao acamamento não se manifestaram.

Ao avaliar o diâmetro do colmo, que, além de suportar as folhas e partes florais, é considerado órgão de reserva da planta de milho, os híbridos que se destacaram foram Biogene $7061 \mathrm{H}^{\circledR}$, Agroeste 1596 VT PRO ${ }^{\text {TM }}$, Dekalb 390 VT PRO ${ }^{\text {TM }}$ e Biogene 7049 $\mathrm{H}^{\circledR}$, corroborando com Dotto et al. (2010), que encon- traram efeito apenas dos híbridos quando submetidos à inoculação e doses de nitrogênio em cobertura avaliando o diâmetro do colmo.

Para o teor de clorofila total, os dados corroboram com Hurtado et al. (2010), que relatam que os híbridos utilizados podem afetar as leituras do clorofilômetro. Nota-se, na Tabela 2, que os híbridos que proporcionaram leituras superiores aos demais foram Riber 9006 VT PRO ${ }^{\mathrm{TM}}$, Dekalb 390 VT PRO ${ }^{\mathrm{TM}}$ e Biogene $7061 \mathrm{H}^{\circledR}$, demonstrando a eficiência destes híbridos na assimilação de nitrogênio.

A atividade da enzima redutase do nitrato dosada nas folhas foi afetada apenas pelo fator híbridos (Tabela 2). Na primeira época em estádio entre V4V6, apenas o híbrido Biogene 7049 Herculex $^{\circledR}$ apresentou menor atividade média em relação aos demais, que foram superiores e não diferiram entre si. Na época em pré-pendoamento, estádio VT, os híbridos com atividades enzimáticas superiores foram Dekalb 390 VT PROTM, Biogene 7061 Herculex $^{\circledR}$, Agroeste 1581

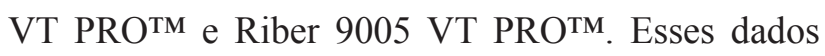
corroboram com Purcino et al. (1994), que, ao estudarem 15 genótipos de milho, encontraram diferença significativa entre os mesmos, mas não verificaram efeito das doses de nitrogênio testadas sobre a atividade desta enzima.

Apesar de outros trabalhos citarem o efeito da inoculação com Azospirillum na atividade da enzima redutase do nitrato (Sala, 2007; El-Komy et al., 2003), no presente estudo não se observou tal efeito. O não efeito da inoculação com Azospirillum também foi citado por Reis Júnior et al. (2008), que relataram que a variabilidade dos resultados em trabalhos de inoculação com Azospirillum é bastante frequente devido possivelmente à inconsistência à colonização radicular, problemas de sobrevivência do inóculo ou por condições ambientais desfavoráveis à bactéria. 
Tabela 1. Resumo da análise de variância e valores dos quadrados médios de parâmetros de crescimento de milho em função dos híbridos (H) e adubação nitrogenada combinada com inoculação de $A$. brasilense (DI)

\begin{tabular}{|c|c|c|c|c|c|c|c|c|c|c|c|c|}
\hline \multirow{2}{*}{$\begin{array}{l}\text { Fonte de } \\
\text { Variação }\end{array}$} & \multirow{2}{*}{ G.L } & \multicolumn{11}{|c|}{ Quadrados Médios } \\
\hline & & $\begin{array}{c}A R \\
V 4-V 6\end{array}$ & $\mathrm{Vt}$ & ALTP & ALTIE & DCOL & ISPAD & CESP & FILES & GRAFIL & Ml00 & PROD \\
\hline Bloco & 3 & 7,01 & 6,15 & $0,18^{* *}$ & 0,134 & $30,30^{* *}$ & $55,28 *$ & $3,30+*$ & $1,5100^{*}$ & $23,92^{\text {** }}$ & $11,43 * *$ & $3,09 * *$ \\
\hline Hibrido(H) & 9 & $5,23 * *$ & $6,03 * *$ & $0,36^{* *}$ & $0,177 * *$ & $10,90^{* *}$ & $196,60^{k *}$ & $16,08 * *$ & $22,57 * *$ & $83,17 * *$ & $94,60^{* * *}$ & $4,31^{* *}$ \\
\hline Dn+Ino(DI) & 3 & 0,83 & 2,67 & $0,06^{* *}$ & 0,182 & $22,21 * *$ & $644,48^{* *}$ & $12,70^{* *}$ & 0,8217 & $82,60^{* *}$ & 5,2700 & $19,05 * *$ \\
\hline $\mathrm{HXDI}$ & 27 & 2,61 & 2,09 & 0,007 & 0,578 & 1,5177 & 11,929 & 0,5912 & 0,5117 & 5,8073 & 3,3950 & 0,423 \\
\hline Residuo & 117 & 1,95 & 2,11 & 0,011 & 0,719 & 1,5216 & 15,5405 & 0,6116 & 0,3910 & 3,8889 & 2,2353 & 0,321 \\
\hline C.V. $(\%)$ & - & 31,50 & 53,48 & 4,59 & 7,24 & 6,09 & 7,57 & 5,52 & 3,95 & 6,96 & 5,76 & 8,20 \\
\hline
\end{tabular}

${ }^{1} \mathrm{ARN}=$ atividade da redutase do nitrato nos estádios entre V4-V6 e VT; ALTP = altura de planta; ALTIE = altura de inserção da primeira espiga; DCOL = diâmetro basal do colmo; ISPAD = clorofila total; FILES = número de fileiras de grãos por espiga; CESP = comprimento de espiga; GRAFIL = grãos por fileira; M100 = massa de 100 grãos; e PROD = produção de grãos. *- Significativos ao nível de 5\% de probabilidade, pelo teste F. **- Significativo ao nível de $1 \%$ de probabilidade, pelo teste F. ***- GL Bloco $=2$, GL $=$ Resíduo $=78$.

Tabela 2. Efeito dos híbridos sobre as variáveis analisadas.

\begin{tabular}{|c|c|c|c|c|c|c|c|c|c|c|c|}
\hline \multirow{3}{*}{${ }^{1 / H i b r i d o s}$} & \multirow{3}{*}{$\begin{array}{l}{ }^{2} \text { ALTP } \\
\text { (m) }\end{array}$} & \multirow{3}{*}{$\begin{array}{l}\text { ALTIES } \\
\text { (m) }\end{array}$} & \multirow{3}{*}{$\begin{array}{l}\text { DCOLM } \\
(\mathrm{mm})\end{array}$} & \multirow{3}{*}{$\begin{array}{l}\text { CLOR } \\
\text { (SPAD) }\end{array}$} & \multirow{2}{*}{\multicolumn{2}{|c|}{$\begin{array}{l}\text { ARN } \\
\left.\mathrm{NO}_{2}^{-} \mathbf{h}^{-1} \mathrm{~g}^{-1} \mathrm{mf}\right)\end{array}$}} & \multirow{3}{*}{$\begin{array}{l}\text { CESP } \\
(\mathrm{cm})\end{array}$} & \multirow[t]{3}{*}{ FILESP } & \multirow[t]{3}{*}{ GRAFIL } & \multirow{3}{*}{$\begin{array}{l}\text { M100 } \\
\text { (g) }\end{array}$} & \multirow{3}{*}{$\begin{array}{l}\text { PROD } \\
\left(\mathrm{Mg} \mathrm{ha}^{-1}\right)\end{array}$} \\
\hline & & & & & & & & & & & \\
\hline & & & & & V4-V6 & Vt & & & & & \\
\hline DKB390 & $2,21 \mathrm{c}$ & $1,25 \mathrm{a}$ & $20,88 \mathrm{a}$ & $56,24 \mathrm{a}$ & $4,04 \mathrm{a}$ & $3,87 \mathrm{a}$ & $13,81 d$ & $16,44 \mathrm{c}$ & $25,50 \mathrm{~d}$ & $26,73 \mathrm{c}$ & $6,67 \mathrm{c}$ \\
\hline DKB310 & $2,26 \mathrm{c}$ & $1,25 \mathrm{a}$ & $20,21 \mathrm{~b}$ & $51,44 \mathrm{c}$ & $5,58 \mathrm{a}$ & $2,62 \mathrm{~b}$ & $14,94 \mathrm{~b}$ & $16,44 \mathrm{c}$ & $27,51 \mathrm{c}$ & $26,87 \mathrm{c}$ & $7,45 \mathrm{a}$ \\
\hline BG7046 & $2,48 \mathrm{a}$ & $1,22 \mathrm{~b}$ & $20,39 \mathrm{~b}$ & $53,33 \mathrm{~b}$ & $4,28 \mathrm{a}$ & $1,82 \mathrm{~b}$ & $14,23 \mathrm{c}$ & $16,71 \mathrm{~b}$ & $30,11 \mathrm{~b}$ & $23,75 \mathrm{~d}$ & $7,56 \mathrm{a}$ \\
\hline BG7049 & $2,26 \mathrm{c}$ & $1,18 \mathrm{~b}$ & $20,85 \mathrm{a}$ & $50,49 \mathrm{c}$ & $2,98 \mathrm{~b}$ & $2,15 \mathrm{~b}$ & $12,46 \mathrm{~d}$ & $14,71 \mathrm{e}$ & $28,36 \mathrm{c}$ & $25,74 \mathrm{c}$ & $6,35 \mathrm{c}$ \\
\hline BG7061 & $1,93 \mathrm{~d}$ & $0,95 \mathrm{~d}$ & $21,35 \mathrm{a}$ & $55,96 \mathrm{a}$ & $4,22 \mathrm{a}$ & $3,32 \mathrm{a}$ & $14,98 \mathrm{~b}$ & $14,13 \mathrm{f}$ & $33,52 \mathrm{a}$ & $24,35 \mathrm{~d}$ & $5,92 \mathrm{~d}$ \\
\hline BG7037 & $2,33 \mathrm{~b}$ & $1,16 \mathrm{~b}$ & $19,96 \mathrm{~b}$ & $51,64 \mathrm{c}$ & $4,72 \mathrm{a}$ & $2,21 \mathrm{~b}$ & $14,09 \mathrm{c}$ & $15,38 \mathrm{~d}$ & $28,09 \mathrm{c}$ & $24,81 \mathrm{~d}$ & $6,60 \mathrm{c}$ \\
\hline AS1581 & $2,46 \mathrm{a}$ & $1,29 \mathrm{a}$ & $20,04 \mathrm{~b}$ & $49,21 \mathrm{c}$ & $4,50 \mathrm{a}$ & $3,26 \mathrm{a}$ & $14,28 \mathrm{c}$ & $17,78 \mathrm{a}$ & $28,95 \mathrm{c}$ & $21,75 \mathrm{e}$ & $7,19 \mathrm{~b}$ \\
\hline AS1596 & $2,30 \mathrm{~b}$ & $1,19 \mathrm{~b}$ & $21,02 \mathrm{a}$ & $45,53 \mathrm{~d}$ & $4,55 \mathrm{a}$ & $2,42 \mathrm{~b}$ & $13,81 \mathrm{c}$ & $16,98 \mathrm{~b}$ & $27,33 \mathrm{c}$ & $26,45 \mathrm{c}$ & $7,32 \mathrm{a}$ \\
\hline RB9005 & $2,26 \mathrm{c}$ & $1,04 \mathrm{c}$ & $19,25 \mathrm{c}$ & $50,34 \mathrm{c}$ & $4,71 \mathrm{a}$ & $3,26 \mathrm{a}$ & $15,58 \mathrm{a}$ & $14,71 \mathrm{e}$ & $27,97 \mathrm{c}$ & $28,39 \mathrm{~b}$ & $7,01 \mathrm{~b}$ \\
\hline RB9006 & $2,31 \mathrm{~b}$ & $1,14 \mathrm{~b}$ & $18,69 \mathrm{c}$ & $56,48 \mathrm{a}$ & $4,76 \mathrm{a}$ & $2,02 \mathrm{~b}$ & $14,73 \mathrm{~b}$ & $15,15 \mathrm{~d}$ & $25,80 \mathrm{~d}$ & $30,33 \mathrm{a}$ & $7,02 \mathrm{~b}$ \\
\hline
\end{tabular}

Médias seguidas de mesma letra na coluna não diferem entre si pelo teste de Scott-Knott (5\%); ${ }^{1}$ Híbridos Dekalb (DKB), Agroeste (AS) e Riber (RB) evento transgênico VT PRO ${ }^{\mathrm{TM}}$ Biogene (BG) evento transgênico Herculex ${ }^{\circledR}$ e Biogene 7046 convencional; ${ }^{2} \mathrm{ALTP}=$ altura da planta; ALTIES = altura de inserção da primeira espiga; DCOLM = diâmetro basal do colmo; $\mathrm{CLOR}=\mathrm{clorofila}$ total; $\mathrm{ARN}=$ atividade da enzima redutase do nitrato nos estádios entre V4-V6 e VT; CESP = comprimento da espiga; FILESP = fileiras por espiga; GRAFIL = grãos por fileira; M100 = massa de 100 grãos; e PROD = produção de grãos.

Os componentes de produção de milho relacionados às espigas (Tabela 2) mostraram o efeito de cada híbrido nas variáveis estudadas pelo teste de média. $\mathrm{O}$ híbrido Riber 9005 VT PRO ${ }^{\text {TM }}$ teve espigas com maior comprimento médio, destacando-se dos demais híbridos. Enquanto, para a variávelnúmero defileiras de grãos por espiga, o híbrido Agroeste 1581 VT PRO ${ }^{\mathrm{TM}}$ deteve a maior média, diferenciando-se dos demais híbridos. 
Essas duas variáveis também foram analisadas por Cruz et al. (2008) em cinco cultivares de milho sob diferentes doses de nitrogênio e os autores relataram o efeito significativo das mesmas. Segundo eles, esses componentes são determinados na segunda semana após a emergência, quando se inicia a formação dos primórdios da espiga. A falta de água e nutrientes nesta fase pode afetar esses componentes. Porém, como as condições experimentais foram as mesmas para todas as cultivares, as diferenças obtidas provieram da influência genética de cada cultivar. Supõe-se que o mesmo ocorreu no presente trabalho.

Os valores médios da massa de 100 grãos indicaram variações significativas apenas entre os híbridos (Tabela 2), sendo o híbrido Riber 9006 VT PROTM $^{\text {TM }}$ superior aos demais híbridos estudados. Segundo Ohland et al. (2005), a massa de 100 grãos é uma característica influenciada pelo genótipo, pela disponibilidade de nutrientes e pelas condições climáticas durante o enchimento de grãos. No presente trabalho, foi possível perceber o efeito apenas dos genótipos (híbridos) para tal variável.

A produção de grãos variou significativamente entre os híbridos, sendo o grupo dos híbridos com produção superior aos demais composto pelos materiais Biogene 7046, Dekalb 310 VT PRO ${ }^{\text {TM }}$ e Agroeste $1596 \mathrm{VT}^{\mathrm{PRO}}{ }^{\mathrm{TM}}$ (Tabela 2). Esses materiais foram os mais responsivos nas condições em estudo, porém não foi possível determinar quais dos híbridos responderam à inoculação em razão da não interação entre os fatores.

Em experimento com dois híbridos, ausência e presença de inoculação e três doses de nitrogênio em cobertura, Dotto et al. (2010) também não encontraram efeito significativo da inoculação com a bactéria Herbaspirillum seropedicae. Porém, evidenciaram o efeito dos híbridos frente à inoculação devido à interação entre esses fatores, sendo que um dos híbridos apresentou um incremento de $8,6 \%$ na produção de grãos em relação ao outro quando os mesmos foram inoculados.

Os resultados do fator adubação nitrogenada em cobertura e inoculação se encontram na Tabela 3. O não efeito da inoculação com Azospirillum brasilense pode ser notado por não haver diferença significativa entre os tratamentos T1 e T2, não confirmando o que foi relatado por Dobbelaere et al. (2001), que verificaram que os efeitos positivos da inoculação são mais consistentes em baixos níveis de adubação nitrogenada. Já para os tratamentos T3 e T4, acredita-se que os incrementos obtidos ocorreram em função da aplicação de adubação nitrogenada em cobertura.

Embora vários trabalhos tenham demonstrado as inúmeras atuações do gênero Azospirillum sobre as plantas, a inconsistência dos resultados positivos com rizobactérias promotoras de crescimento vegetal (RPCV), principalmente em condições de campo, é frequente (Leben et al., 1987). As possíveis causas disto se devem, segundo Antoun et al. (1998), à complexidade das interações envolvidas entre a planta, a bactéria introduzida e os demais componentes da microbiota rizosférica, dentre outros fatores anteriormente citados neste texto.

Quanto ao efeito das doses de nitrogênio em cobertura, observa-se que a altura da planta e o diâmetro basal do colmo foram incrementados. Porém, não houve diferenciação significativa entre as duas doses testadas (T3 e T4) para tais variáveis (Tabela 3). Segundo Castro et al. (2008), o nitrogênio influencia diretamente a divisão e a expansão celulares e o processo fotossintético. Desta forma, plantas bem nutridas em nitrogênio tendem a um maior desenvolvimento vegetativo. 
As doses de nitrogênio em cobertura proporcionaram maior índice de clorofila total (SPAD) (Tabela 3) em relação ao tratamento sem cobertura, sendo que a dose de $70 \mathrm{~kg} \mathrm{ha}^{-1}$ de nitrogênio em cobertura foi significativamente superior à dose de 35 $\mathrm{kg} \mathrm{ha}^{-1}$ de nitrogênio em cobertura. Esses dados corroboram com Kappes et al. (2013), que verificaram efeito da aplicação de $90 \mathrm{~kg} \mathrm{ha}^{-1}$ de $\mathrm{N}$ em cobertura quando comparado à não aplicação do nutriente em cobertura. Além do efeito do nitrogênio em cobertura, Kappes et al. (2013), ao realizarem três leituras nos estádios V5, V8 e pleno florescimento, verificaram o efeito da inoculação com $A$. brasilense na primeira leitura. Porém, este resultado não se manteve para as demais leituras. No presente estudo, a leitura foi realizada no período reprodutivo e não foi observado efeito da inoculação.

Para os componentes da produção relacionados à espiga, o aumento das doses de $\mathrm{N}$ via adubação de cobertura resultou em espigas mais compridas, com incrementos significativos quando comparados à não aplicação de $\mathrm{N}$ em cobertura (Tabela 3). Já para grãos por fileira, as doses de nitrogênio em cobertura também geraram incrementos significativos em relação à não aplicação de $\mathrm{N}$ em cobertura, porém não houve diferença significativa no número de grãos por fileira entre as doses de 70 e $35 \mathrm{~kg} \mathrm{ha}^{-1}$ de $\mathrm{N}$ em cobertura (Tabela 3).

Esses dados relacionados à espiga corroboram com Carmo et al. (2012), que descreveram equações lineares positivas em resposta ao aumento das doses de nitrogênio e verificaram aumentos no comprimento das espigas e no número de grãos por fileira. De acordo com Ritchie et al. (2003), no momento da definição do número de óvulos e do tamanho da espiga (estádio V12), as deficiências de umidade e nutrientes podem reduzir seriamente o número potencial de sementes e o tamanho das espigas colhidas, o que explica os menores comprimento de espigas e número de grãos por fileira nos tratamentos $\mathrm{T} 1 \mathrm{e} \mathrm{T} 2$, que receberam apenas $30 \mathrm{~kg}$ $\mathrm{ha}^{-1}$ de $\mathrm{N}$ na semeadura.

Para a produção de grãos, os tratamentos sem inoculação e com inoculação, ambos com adubação nitrogenada apenas em semeadura, não diferiram significativamente entre si, demonstrando a não influência da inoculação com A. brasilense. Esses dados corroboram com Repke et al. (2013), que citaram a não

Tabela 3. Efeito da adubação nitrogenada em cobertura e inoculação sobre as características agronômicas.

\begin{tabular}{ccccccc}
\hline Tratamentos & $\begin{array}{c}{ }^{1 /} \text { ALTP } \\
(\mathbf{m})\end{array}$ & $\begin{array}{c}\text { DCOL } \\
(\mathbf{m m})\end{array}$ & $\begin{array}{c}\text { CLOR } \\
(\text { SPAD })\end{array}$ & $\begin{array}{c}\text { CESP } \\
(\mathbf{c m})\end{array}$ & GRAFIL & $\begin{array}{c}\text { PROD } \\
\left.\mathbf{( M g ~ h a}^{\mathbf{- 1}}\right)\end{array}$ \\
\hline $\mathrm{T} 1$ & $2,27 \mathrm{~b}$ & $19,76 \mathrm{~b}$ & $49,33 \mathrm{c}$ & $13,71 \mathrm{c}$ & $26,98 \mathrm{~b}$ & $6,42 \mathrm{c}$ \\
$\mathrm{T} 2$ & $2,24 \mathrm{~b}$ & $19,51 \mathrm{~b}$ & $48,07 \mathrm{c}$ & $13,69 \mathrm{c}$ & $27,23 \mathrm{~b}$ & $6,28 \mathrm{c}$ \\
$\mathrm{T} 3$ & $2,32 \mathrm{a}$ & $20,74 \mathrm{a}$ & $54,43 \mathrm{~b}$ & $14,46 \mathrm{~b}$ & $29,16 \mathrm{a}$ & $7,16 \mathrm{~b}$ \\
T4 & $2,32 \mathrm{a}$ & $21,05 \mathrm{a}$ & $56,46 \mathrm{a}$ & $14,83 \mathrm{a}$ & $29,90 \mathrm{a}$ & $7,77 \mathrm{a}$ \\
\hline
\end{tabular}

Médias seguidas de mesma letra na coluna não diferem entre si pelo teste de Scott-Knott $(5 \%)$. ${ }^{1} \mathrm{ALTP}=$ altura da planta; DCOL $=$ diâmetro basal do colmo; CLOR = Clorofila total; CESP = comprimento da espiga; GRAFIL = grãos por fileira; e PROD = Produção de grãos. Onde: T1: sem cobertura e sem inoculação; T2: sem cobertura e com inoculação de $A$. brasilense; T3: aplicação de 35 kg ha-1

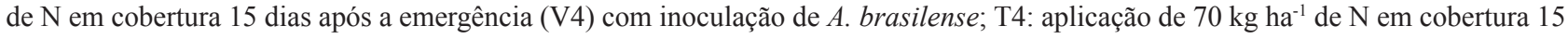
dias após a emergência (V4) com inoculação de $A$. brasilense. 
interferência da aplicação de Azospirillum brasilense via tratamento de sementes, acompanhada ou não de doses de nitrogênio sintético. Resultado divergente foi obtido por Braccini et al. (2012), que verificaram que, com a redução da adubação nitrogenada, a inoculação com $A$. brasilense proporcionou incremento da produção de grãos de milho.

No presente estudo, percebe-se incremento significativo na produção nos tratamentos que receberam adubação nitrogenada em cobertura, quando comparados aos que não receberam (Tabela 3), sendo que a maior dose proporcionou a maior produção de grãos, diferindo significativamente da dose de 35 $\mathrm{kg} \mathrm{ha}^{-1}$ de $\mathrm{N}$ em cobertura. Esses resultados estão de acordo com Repke et al. (2013), que detectaram aumento na produtividade de grãos em função de doses de $\mathrm{N}$ em cobertura.

Com o substancial incremento nas características morfológicas e nos componentes de produção relacionados à espiga pela aplicação de nitrogênio em cobertura, percebe-se a importância deste nutriente no crescimento e desenvolvimento da planta de milho, resultando assim em maiores produtividades de grãos.

\section{Conclusões}

A inoculação com Azospirillum brasilense "per se" não gerou incrementos nas variáveis analisadas.

A adubação nitrogenada em cobertura influencia significativamente o desenvolvimento das plantas de milho, resultando em aumento na produtividade de grãos.

Os híbridos Biogene 7046, Dekalb 310 VT $\mathrm{PRO}^{\mathrm{TM}}$ e Agroeste $1596 \mathrm{VT}^{\mathrm{PRO}}{ }^{\mathrm{TM}}$ foram os mais produtivos nas condições em estudo.

\section{Referências}

ANTOUN, H.; BEACUCHAMP, C. J.; GOUSSARD, N.; CHABOT, R.; LALANDE, R. Potential of Rizobium and Bradyrhizobium species as plant growth promoting rhizobacteria on non-legumes: effect on radishes (Raohnus sativus L.). Plant and Soil, The Hague, v. 204, p. 57-67, 1998.

DOI: $10.1023 / \mathrm{A}: 1004326910584$.

BASHAN, Y.; HOLGUIN, G.; DE-BASHAN, L. E. Azospirillum-plant relations physiological, molecular, agricultural, and environmental advances (1997-2003). Canadian Journal of Microbiology, Ottawa, v. 50, n. 8, p. 521-577, 2004.

DOI: $10.1139 / \mathrm{w} 04-035$.

BRACCINI, A. L.; DAN, L. G. M.; PICCININ, G. G.; ALBRECHT, L. P.; BARBOSA, M. C.; ORTIZ, A. H. Seed inoculation with Azospirillum brasilense, associated with the use of bio regulators in maize. Revista Caatinga, Mossoró, v. 25, n. 2, p. 58-64, 2012.

CARMO, M. S.; CRUZ, S. C. S.; SOUZA, E. J.; CAMPOS, L. F. C.; MACHADO, C. G. Doses e fontes de nitrogênio no desenvolvimento e produtividade da cultura do milho doce (Zea mays convar. saccharata var. rugosa). Bioscience Journal, Uberlândia, v. 28, n. 1, p. 223-231, 2012.

CASTRO, P. R. C.; KLUGE, R. A.; SESTARI, I. Manual de fisiologia vegetal: fisiologia de cultivos. São Paulo: Agronômica Ceres, 2008. 864 p.

CRUZ, S. C. S.; PEREIRA, F. R. S.; SANTOS, J. R.; ALBUQUERQUE, A. W.; PEREIRA, R. G. Adubação nitrogenada para o milho cultivado em sistema plantio direto, no Estado de Alagoas. Revista Brasileira de Engenharia Agrícola e Ambiental, Campina Grande, v. 12, n. 1, p. 62-68, 2008.

DOI: $10.1590 / \mathrm{S} 1415-43662008000100009$.

DOBBELAERE, S.; CROONENBORGHS, A.; THYS, A.; PTACEK, D.; VANDERLEYDEN, J.; DUTTO, P.; LABANDERA-GONZALEZ, C.; CABALLEROMELLADO, J.; AGUIRRE, J. F.; KAPULNIK, Y.; 
BRENER, S.; BURDMAN, S.; KADOURI, D.; SARIG, S.; OKON, Y. Responses of agronomical important crops to inoculation with Azospirillum. Australian Journal of Plant Physiology, Melbourne, v. 28, n. 9, p. 871-879, 2001. DOI: 10.1071/PP01074.

DOTTO, A. P.; LANA, M. C.; STEINER, F.; FRANDOLOSO, J. F. Produtividade do milho em resposta à inoculação com Herbaspirillum seropedicae sob diferentes níveis de nitrogênio. Revista Brasileira de Ciências Agrárias, Recife, v. 5, n. 3, p. 376-382, 2010. DOI: 10.5039/agraria.v5i3a898.

EL-KOMY, H. M.; HAMDIA, M. A.; ABD EL-BAKI, G. $\mathrm{K}$. Nitrate reductase in wheat plants grown under water stress and inoculated with Azospirillum spp. Biologia Plantarum, Praha, v. 46, n. 2, p. 281-287, 2003.

DOI: $10.1023 / \mathrm{A}: 1022819114860$.

FERREIRA, D. F. Sisvar: a computer statistical analysis system. Ciência e Agrotecnologia, Lavras, v. 35, n. 6, p. 1039-1042, 2011.

\section{DOI: $10.1590 / \mathrm{S} 1413-70542011000600001$.}

HUNGRIA, M.; CAMPO, R. J.; SOUZA, E. M.; PEDROSA, F. O. Inoculation with selected strains of Azospirillum brasilense and A. lipoferum improves yields of maize and wheat in Brazil. Plant and Soil, The Hague, v. 331, n. $1 / 2$, p. $413-425,2010$

DOI: $10.1007 / \mathrm{s} 11104-009-0262-0$.

HURTADO, S. M. C.; SILVA, C. A.; RESENDE, A. V.; CORAZZA, E. J.; SHIRATSUCHI, L. S.; HIGASHIKAWA, F. S. Sensibilidade do clorofilômetro para diagnóstico nutricional de nitrogênio no milho. Ciência e Agrotecnologia, Lavras, v. 34, n. 3, p. 688-697, 2010. DOI: $10.1590 / \mathrm{S} 1413-70542010000300023$.

KAPPES, C.; ARF, O.; ARF, M.; FERREIRA, J. P.; DAL BEM, E. A.; PORUTGAL, J. R.; VILELA, R. G. Inoculação de sementes com bactéria diazotrófica e aplicação de nitrogênio em cobertura e foliar em milho. Semina: Ciências Agrárias, Londrina, v. 34, n. 2, p. 527 538,2013

DOI: $10.5433 / 1679-0359.2013 v 34 n 2 p 527$.
KLEPPER, L.; FLESCER, D.; HAGEMAN, R. D. Generation of reduced nicotinamide adenine dinucleotide for nitrate reduction in green leaves. Plant Physiology, Bethesda, v. 48, n. 5, p. 580-590, 1971.

LI, Y.; DONG, Y.; NIU, S.; CUI, D. The genetics relationships among plant-height thaits found using multiple trait QTL mapping of a dent corn and popcorn cross. Genome, Toronto, v. 50, n. 4, p. 357-364, 2007. DOI: $10.1139 / \mathrm{g} 07-018$.

LEBEN, S. D.; WADI, J. A.; EASTON, G. D. Effects of Pseudomonas fluorescens on potato growth and control of Verticillium dahlia. Phytopathology, Saint Paul, v. 77, n. 11, p. 1592-1595, 1987.

OHLAND, R. A. A.; SOUZA, L. C. F.; HERNANI, L. C.; MARCHETTI, M. E.; GONÇALVEZ, M. C. Culturas de cobertura do solo e adubação no milho em plantio direto. Ciência Agrotecnologia, Lavras, v. 29, n. 3, p. 538-544, 2005. DOI: $10.1590 / \mathrm{S} 1413-70542005000300005$.

PURCINO, A. A. C.; MAGNAVACA, R.; MACHADO, A. T.; MARRIEL, I. E. Atividade da redutase do nitrato em genótipos antigos e modernos de milho, cultivados sob dois níveis de nitrogênio. Revista Brasileira de Fisiologia Vegetal, Londrina, v. 6, n. 1, p. 41-46, 1994.

REIS JÚNIOR, F. B.; MACHADO, C. T. T.; MACHADO, A. T.; SODEK, L. Inoculação de Azospirillum amazonense em dois genótipos de milho sob diferentes regimes de nitrogênio. Revista Brasileira de Ciência do Solo, Campinas, v. 32, n. 3, p. 1139-1146, 2008.

DOI: $10.1590 / \mathrm{S} 0100-06832008000300022$.

RENGEL, Z. Genetic control or root exudation. Plant and Soil, The Hague, v. 245, n. 1, p. 59-70, 2002. DOI: 10.1023/A:1020646011229.

REPKE, R. A.; CRUZ, S. J. S.; SILVA, C. J.; FIGUEIREDO, P. G.; BICUDO, S. J. Eficiência da Azospirillum brasilense combinada com doses de nitrogênio no desenvolvimento de plantas de milho. Revista Brasileira de Milho e Sorgo, Sete Lagoas, v. 12, n. 3, p. 214-226, 2013. DOI: $10.18512 / 1980-6477 /$ rbms.v12n3p214-226. 
RITCHIE, S. W.; HANWAY, J. J.; BENSON, G. O. Como a planta de milho se desenvolve. Informações Agronômicas, Piracicaba, n. 103, p. 1-20, set. 2003. Encarte. Disponível em: $\quad<$ http://brasil.ipni.net/ipniweb/region/brasil.nsf/0/ DE02520B8765B8D683257AA0003C46A6/\$FILE/ Encarte103.pdf> Acesso em: 27 jan. 2014.

SALA, V. N. R.; BRAN, E. J. B. N.; FREITAS, J. G.; SILVEIRA, A. P. D. Resposta de genótipos de trigo à inoculação de bactérias diazotróficas em condições de campo. Pesquisa Agropecuária Brasileira, Brasília, DF, v. 42 , n. 6 , p. 833-842, 2007.

DOI: $10.1590 / \mathrm{S} 0100-204 X 2007000600010$.

SOUZA, D. M. G.; LOBATO, E. Cerrado: correção do solo e adubação. 2. ed. Brasília, DF: Embrapa Informação Tecnológica; Planaltina, DF: Embrapa Cerrados, 2004. $416 \mathrm{p}$. 